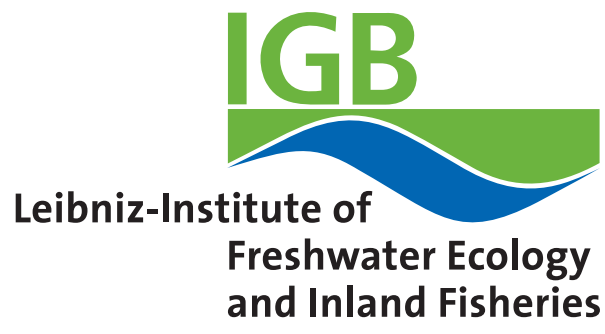

\title{
Are some sharks more social than others? Short- and long-term consistencies in the social behavior of juvenile lemon sharks
}

Jean Sebastian Finger (D) https://orcid.org/0000-0002-4134-7073,

Tristan L. Guttridge,

Alexander D. M. Wilson,

Samuel H. Gruber,

Jens Krause (DD https://orcid.org/0000-0002-1289-2857

DOI

10.1007/s00265-017-2431-0

Original publication date

29 December 2017 (First Online)

Document version

Author's accepted manuscript version

\section{Published in}

Behavioral Ecology and Sociobiology

\section{Citation}

Finger JS, Guttridge TL, Wilson ADM, Gruber SH, Krause J. Are some sharks more social than others?: Short- and long-term consistencies in the social behavior of juvenile lemon sharks. Behavioral Ecology and Sociobiology. 2018;72(1):art. 17. 
1 Are some sharks more social than others? Short and long-term consistencies in the social behavior

2 of juvenile lemon sharks

3 Authors: J.S. Finger ${ }^{1,2,3^{*}}$, T.L. Guttridge ${ }^{2}$, A.D.M. Wilson ${ }^{4}$, S.H. Gruber ${ }^{2}$, J. Krause ${ }^{1,3}$

4

$5{ }^{1}$ Humboldt-Universität zu Berlin, Faculty of Life Sciences, Albrecht Daniel Thaer-Institut, Berlin,

6 Germany

$7 \quad{ }^{2}$ Bimini Biological Field Station Foundation, Bahamas

$8 \quad{ }^{3}$ Leibniz-Institute of Freshwater Ecology and Inland Fisheries, Berlin, Germany

$9 \quad{ }^{4}$ School of Life and Environmental Sciences, University of Sydney, New South Wales 2006, Australia.

10

11 Correspondence:

12 J.S. Finger,

13 Bimini Biological Field Station Foundation,

$149300 \mathrm{SW} 99 \mathrm{St}$,

15 Miami FL 33176-2050, U.S.A.

16 js.finger@yahoo.fr

17 Orcid ID: orcid.org/0000-0002-4134-7073 


\section{Abstract:}

21 Despite substantial research interest in understanding individual-level consistency in behavioral attributes,

22 significant knowledge gaps remain across traits and taxa. For example, relatively few studies have looked 23 at social personality in large marine species such as elasmobranchs and whether or not individual 24 differences in behavior are maintained in unstable social groups (i.e. fission-fusion dynamics). However, it 25 is important to investigate this topic in other model species than the usually small species with short 26 generation times typically investigated in these areas of behavioral ecology. Indeed, studies on 27 ecologically diverse taxa could provide mechanistic insights into the emergence and maintenance of 28 animal personality and dynamics of social groups in animals. In addition, understanding social behavior at 29 the group- and individual-level could improve conservation management of these large animals with long 30 generation times (e.g. removal of particular behavioral types by fisheries practices). Here, we investigated

31 consistent individual differences in sociability in wild juvenile lemon sharks (Negaprion brevirostris) over

32 both short- (4 to 18 days) and long-term (4 months) sampling periods. Individual sharks were observed in 33 social groups and scored according to the number of social interactions performed during observations.

34 Despite variable individual group compositions between repeated trials, sharks showed consistent 35 individual differences in their social behavior over both time scales. These results suggest reduced 36 plasticity and highlight individuality as an important explanatory variable for the social dynamics of 37 juvenile lemon sharks. In addition, long term stability observed in this wild population demonstrates the 38 importance of personality in the daily behavioral repertoire of juvenile lemon sharks. Our results are 39 discussed in the context of other shark studies and taxonomic groups and potential avenues for future 40 research are proposed. 


\section{SIGNIFICANCE STATEMENT}

45 This study investigated the social personality axis in a wild population of juvenile lemon sharks. First, we 46 demonstrated consistent individual differences in their tendency to socialize. Second, we showed that 47 individuals maintained their differences over a four-month period in the wild. Finally, we found that 48 individual social behaviors were maintained despite being tested in variable group compositions. These

49 results highlight the importance of individuality in the social dynamic of a poorly investigated animal and 50 suggest personality as an important aspect of juvenile lemon sharks' everyday life over a relatively long51 term period.

52 Key words: Fission-fusion, follower, group phenotype, leadership, personality, social dynamics.

\section{INTRODUCTION}

55 Animal personality, consistent individual differences in behavior across time and contexts, has been 56 described in a broad spectrum of taxa (Gosling 2001; Sih et al. 2004; Reale et al. 2007) and is recognized 57 as a fundamental aspect of ecology and evolution (Sih et al. 2012; Wolf and Weissing 2012). Furthermore, 58 it is now understood that individual differences need to be incorporated within conservation management 59 programs (Conrad et al. 2011; Mittelbach et al. 2014). However, a primary obstacle for many species, 60 including large-bodied marine animals such as sharks, lies in the fact that not enough data exist to 61 understand if and how the inclusion of personality could benefit such programs. This issue can be 62 problematic considering the sensitivity of mega-fauna to anthropogenic harvest and overexploitation (e.g. 63 Lewison et al. 2004; Estes et al. 2011). For example, sharks have only recently received attention from an 64 individual-based behavioral standpoint (e.g. Huveneers et al. 2013; Vaudo et al. 2014; Matich and 65 Heithaus 2015; Towner et al. 2016; Finger et al. 2017) and a behavioral consistency standpoint in the last 66 few years (Jacoby et al. 2014; Wilson et al. 2015; Byrnes and Brown 2016; Byrnes et al. 2016a, b; Finger 67 et al. 2016). In terms of consistency in individual social behavior, what little information there is remains 
unclear and in need of further study. For example, Jacoby et al. (2014) found consistent individual differences in social network position in a captive population of juvenile catsharks (Scyliorhinus canicula) but significance was lost once the group effect was controlled for. In contrast, Wilson et al. 2015 found no evidence of consistency in social network position in wild juvenile lemon sharks (Negaprion brevirostris).

Sharks are generally large-bodied, long-lived animals with a large brain to body mass ratio (Northcutt 1977; Yopak et al. 2007). They exhibit slow growth and reproduction rates, while occupying a relatively high trophic position (e.g. Stevens et al. 2000; Dulvy et al. 2014). As a result, sharks could be an interesting addition to smaller aquatic vertebrates (with relatively fast generational turn-over) usually studied within the animal personality framework. For instance, while predation is often a factor underlying the evolution of social grouping, as frequently seen in teleost fishes (Krause and Ruxton 2002), some gregarious shark species such as the scalloped hammerhead (Sphyrna lewini; Klimley 1985) actually experience low risk of predation overall. It is then conceivable that alternative selective pressures shaped the evolution of social behavior in many shark species. As similar assumptions could be drawn for individual differences in sociability, it is important to further investigate personality in sharks. In addition, expanding this research to wild populations and long-term observations will help to determine the importance of personality to sharks' everyday life. Because sociability has already been described in different shark species (e.g. Myrberg and Gruber 1974; Klimley 1985; Guttridge et al. 2009; Guttridge et al. 2011; Jacoby et al. 2012a; Mourier et al. 2012, 2017), it is a critical step for the development of better management programs. Indeed, the removal of particular personality types (Biro and Post 2008; Sutter et al. 2012; Biro and Sampson 2015) through fisheries might have unknown consequences for the food web, ecosystems and environmental management. For example, the documented risk posed by fishery targeting aggregations (Mucientes et al. 2009; Jacoby et al. 2012a), could conceivably select against social 90 individuals (i.e. higher tendency to aggregate).

91 We investigated the presence of consistent individual differences in the social behavior of wild juvenile 92 lemon sharks by testing groups of six individuals. However, this study differs from those previously 
93 conducted in several aspects. First this study assessed consistency over both short (4-18 days) and long94 term (4 months) periods in wild sharks. Long-term observations have obvious benefits (Stamps and 95 Groothuis 2010) but are rarely conducted on wild animal populations (Archard and Braithwaite 2010) and 96 especially with such long-lived species. However, a major difficulty in generating long-term data sets is 97 that individuals disperse or suffer mortality (Gruber et al. 2001), which can lead to different individuals 98 being caught during a given sampling event. To account for this here, except for a subset of the data, 99 individuals were haphazardly assigned to groups for retests, leading to variation in individuals' social 100 environments (i.e., group composition). This approach provided the opportunity to determine if observed 101 consistency in tendency to socialize can be attributed to individual differences and is not just a result of 102 group effects and composition (Pritchard et al. 2001; Harcourt et al. 2009b; Kurvers et al. 2009; Cote et al. 103 2012). In addition, changing group composition while testing social personality in captivity reflected rapid 104 changes in social partners commonly observed in juvenile lemon sharks in the wild (Guttridge et al. 2011;

105 Wilson et al. 2015). Indeed, this aspect (among others) of their social dynamic has been shown to 106 resemble that of wild guppies (Poecilia reticulata), a fish species demonstrating social fission-fusion 107 behavior (Wilson et al. 2014, 2015). In summary, we tested the predictions that wild individual juvenile 108 lemon sharks consistently differ in their social behavior over short (5 to 18 days) and long-term (4 109 months) tests and further, that these differences were robust to changes in group composition.

\section{METHOD}

\section{Study site and Sharks}

113 This study was conducted on Bimini $\left(20^{\circ}-28^{\circ} \mathrm{N}, 72^{\circ}-80^{\circ} \mathrm{W}\right)$, situated approximately $85 \mathrm{~km}$ east of the 114 coast of Florida (USA) in The Bahamas. Wild juvenile lemon sharks from two adjacent mangrove-fringed 115 habitats (North Sound and Shark Land) were captured using gillnets (see Manire and Gruber 1991 for 116 details) in June (7-day capture session) and November 2012 (3-day capture session). Upon capture, each 
117 individual was measured (pre-caudal length: PCL), sexed and equipped with a unique color-coded tag (T-

118 bar type, Floy Tag Manufacturing) for visual identification.

119 Lemon sharks were our test subject because they are a common, large coastal species in the western

120 Atlantic. In some locations, they show long-term site attachment (approx. three years) allowing their

121 capture and recapture over extended periods while living in their natural habitat (Morrissey and Gruber

122 1993; Dibattista et al. 2007; Chapman et al. 2009). In addition, they have been successfully used in semi-

123 captive behavioral experiments (e.g. Guttridge et al. 2009; Finger et al. 2016).

Experimental set-up

125 Sharks were housed in a large oval-shaped pen $(10 \times 5 \mathrm{~m})$ constructed just offshore in the North Sound on 126 sand bottom flats. They were given at least four days in the holding pen to acclimatize to captive 127 conditions before beginning the experimental procedure. During holding time, they were fed every three 128 days on a diet of fresh and frozen local fish (Sphyraena barracuda).

129 A channel (length, $4 \mathrm{~m}$ ) linked the experimental pen to the holding pen. The circular experimental pen 130 (diameter, $10 \mathrm{~m}$ ) was equipped with a camera recorder placed $6 \mathrm{~m}$ above the center and operated by a 131 system of ropes. A wooden tower (height, $3 \mathrm{~m}$ ) was placed outside the pen to allow observations (Fig. 1).

132 The day before observation, six sharks, selected to reduce size difference (within PCL $\pm \mathrm{SD}=4.7 \pm 2.73$

$133 \mathrm{~cm}$ ), were ushered into the experimental pen, fed to satiation (to insure similarity of hunger level between 134 individuals) and left overnight to acclimatize to their environment. Sex has been shown to have no 135 influence on social dynamics of juvenile lemon sharks in Bimini (Guttridge et al. 2009, 2011) and was not 136 considered further in the design of this experiment. On the day of observation, the swimming behavior of 137 the six individuals was filmed for 20 minutes. Each individual was marked on their dorsal fins with unique 138 color-coded tags to allow for subsequent identification and tracking during video analyses. Upon 139 completion of filming, sharks were released, or relocated to the holding pen to await further retesting (see 140 below for test periods). 
142 During this study, two rounds of tests were carried out: June and November 2012. In June, individuals

143 were tested only once $(\mathrm{N}=84 ; 41$ females and 43 males, mean pre-caudal length $\pm \mathrm{SD}=51.8 \pm 5.7 \mathrm{~cm})$

144 and then released in their natural habitat. In November, all sharks ( $N=48 ; 19$ females and 29 males, mean

145 pre-caudal length $\pm \mathrm{SD}=54.3 \pm 6.1 \mathrm{~cm}$ ) were tested twice (time between tests: 4 to 18 days; $8.5 \pm 4.3$

146 days), and of these individuals, 23 (14 females and 9 males) had been tested in June previously. Each

147 observation session started at similar water depth (mean depth $\pm \mathrm{SD}=79 \pm 12.4 \mathrm{~cm}$ ), $1.5 \mathrm{hr}$ before or after

148 a slack low tide.

149 Group composition changes occurred haphazardly between June and November tests (23 individuals from

15011 different groups from June were haphazardly allocated to 8 groups in November). Group mixing 151 between test and retests in November consisted of exchanging half of a group (3 individuals) with another 152 half. Such mixing occurred for 4 groups ( $\mathrm{N}=24$ individuals) whereas for 4 other groups composition 153 remained unchanged.

\section{Social interaction observations}

155 During video processing, data were recorded every 30 seconds, across 20-minute observation sessions 156 (thus 40 observations in total); each time the focal individual was recorded as social or asocial. Juvenile 157 lemon shark social behavior is characteristically composed of following or paralleling with other 158 individuals (see Table 1 for definitions). A leading event can be defined as occurring when one individual 159 is being followed but is not paralleling or following another individual (Table 1). As a focal individual 160 being followed might not reflect its wish to socialize, we considered only "active" events of social 161 interaction (i.e. following and paralleling) as a social interaction performed by this individual. Resting and 162 milling (see Table 1) were designated here as non-social events for two reasons. First, resting behavior in 163 juvenile lemon sharks is not well understood and it has been shown that most (>95\%) social interactions 164 occur during active swimming (Guttridge et al. 2009). Second, individuals were considered as social only 
when being notably influenced by another individual. Two (or more) individuals could cross paths but if neither of them modified their swimming movements then they were not considered to be interacting.

167 Each individual's social behavior score was obtained by summing the number of active social events (see 168 below) over the 40 observations. All sharks in the arena were observed in this manner.

169 An algorithm was developed to quantify the social behaviors described above. This tool has also been 170 used to analyze juvenile lemon sharks' social behavior in another study (Keller et al. 2017). Briefly, for 171 each of the 40 observations, this algorithm used position (coordinates of the tip of the snout) and 172 orientation of the six individuals at time $t, t+1$ and $t+2$ second. Orientation was obtained relative to the 173 previous point, therefore, at time t, orientation was obtained by adding a tracking point at $\mathrm{t}-1$ second. 174 Tracking was completed manually by marking the snout of each shark using MtrackJ (Meijering et al. 175 2012) within ImageJ (Rasband 1997). Using these data, the algorithm calculated distances between 176 individuals, along with the differences in orientation and position (front, behind, side by side) between 177 sharks. Additional tracking ( $\mathrm{t}+1$ and $\mathrm{t}+2$ seconds) was used to determine if overtaking occurred, and if a 178 dramatic turn of one shark (creating a large orientation difference at time t) influenced (i.e. following) 179 other individuals (resulting in similar dramatic orientation change of the followers during $t+1$ and $t+2$ ). 180 The resulting values obtained from these calculations allowed the algorithm to define each individual's 181 social behavior as following (within social distance and behind another individual and similar orientation 182 or influenced by this same individual), paralleling (within social distance and side by side or overtaking 183 another individual and similar orientation than this same individual) or asocial (outside of social distance 184 or not being influenced by other individuals). Upon completion, the algorithm provided the total number 185 of social events over the 40 observations (paralleling and following; Table 1) as the individual social score 186 in this investigation. The above algorithm was used to standardize data collection and reduce potential 187 observer bias. 
189 Previous studies used a maximum social distance of either one (Wilson et al. 2015) or four body lengths 190 (Guttridge et al. 2011) when considering social interactions of juvenile lemon sharks in semi-wild or wild 191 conditions. In contrast, 2.5 body lengths between individuals were found to be best in our experimental 192 setup. This value was observed as being the maximum distance at which individuals performed following 193 behavior during preliminary video analyses (distance was calculated using coordinates of sharks in videos 194 and absence or presence of social interaction was determined by two observers).

195 A comparison between social distances (i.e. 1, 2.5 and 4 body lengths) showed that below 2.5 body 196 lengths, a large number of associations were missed but above 2.5 body lengths only very few were added.

198 To control for the reliability of this algorithm, 4 videos that were processed through the algorithm were 199 also analyzed manually. Observers, naïve to the algorithm, were asked to describe each individual social 200 behavior as describe above (to mimic analyses by the algorithm). Social scores obtained from manual 201 observations and the above algorithm were highly correlated (Spearman's rank correlation: $r_{s}=0.96$, $202 \mathrm{~N}=24, \mathrm{P}<0.001$ ) and did not differ significantly (Wilcoxon paired test: $\mathrm{V}=138.5, \mathrm{P}=0.71, \mathrm{~N}=24$ ). We 203 therefore concluded that the algorithm showed results highly similar to those obtained through manual 204 observation and could therefore be confidently applied to the full data set.

206 To test short-term consistency, analyses were performed within the November period overall, then we 207 divided this period into groups of mixed and non-mixed composition. To test long-term consistency, 208 analyses were performed between observations from June and November. We took the first trial of 209 November tests instead of the average between the two trials to minimize the potential of confounding 210 effects (due to habituation, familiarity development etc.). 
212 To investigate consistent individual differences in social behavior, we first used Spearman rank 213 correlation analyses within the different subsets of data described above. If a significant correlation was 214 found (for short-term or long-term data) a permutation analysis was performed. For permutation analyses, 215 individual social scores were randomly sampled from the social groups they were tested in. Therefore, a 216 shark could be assigned only a social score from another shark (or his own) from the same social group. 217 This was applied to June, November first and November second trials. Using this randomly permuted 218 data, correlation tests were performed between trials (e.g. correlation between permutated June and 219 permutated November first trial for long-term tests) and the Spearman's rho estimations extracted. This 220 step was repeated 10,000 times to obtain a distribution of randomly simulated rho for each correlation we 221 were interested in. This distribution was then compared to the observed rho (estimated from original data) 222 by extracting the proportion of simulated rho greater than the observed rho (thereafter referred to as P). If $223 \mathrm{P}$ was found to be smaller or equal to 0.025 , we deemed our observed correlation significant which was

224 used as a demonstration of consistent individual differences. These within-group permutations were 225 necessary to control for a potential effect of pseudo-replication created by testing individuals in groups 226 (Croft et al. 2011) and the possibility that any observed consistency could be due to consistent differences 227 in overall group behavior between trials.

\section{Repeatability}

229 To provide a repeatability score of sociability along with a 95\% confidence interval, the full data set (all 230 trials included) was analyzed using a linear mixed model with individual ID as random factor and sex, 231 size, capture location (i.e. nursery), time in pen before trial and period of observation (June; November) as 232 fixed effects. Social score was normalized using a square root transformation. Normalization of the data 233 allowed the use of the function exactRLRT from the RLRsim package (Scheipl et al. 2008) to test 234 significance of the random term (i.e. individual ID). Repeatability was calculated according to Nakagawa 235 and Schielzeth (2010). The 95\% confidence interval was calculated using the confint function from lme4 
package (Bates et al. 2015). These analyses were performed on the overall data set. All analyses were 237 performed in R v3.2.3 (R Core Team 2015).

\section{RESULTS}

240 Consistency in social behavior was found over short-term periods of several days (Spearman rank 241 correlation: $\mathrm{r}_{\mathrm{s}}=0.43, \mathrm{~N}=48, \mathrm{P}<0.001$, Fig. 2a) and long-term periods of four months (Spearman rank 242 correlation: $r_{s}=0.52, N=23, P=0.01$, Fig. $2 b$ ). The consistency found here was not caused by differences 243 in overall group behavior (permutation analyses: short-term tests: $\mathrm{P}=0.005$; long-term tests: $\mathrm{P}=0.0088$ ).

244 Within short tests, those that did not experience any changes in group composition did not show consistent 245 differences in social behavior (Spearman rank correlation: $\mathrm{r}_{\mathrm{s}}=0.39, \mathrm{~N}=24, \mathrm{P}=0.057$,) whereas individuals 246 that experienced a mixing of groups did (Spearman rank correlation: $r_{s}=0.43, N=24, P<0.05$; Permutation 247 analyses: $\mathrm{P}=0.0094)$. However, individuals from the short-term non-mixed group showed consistent 248 individual differences as well, when one outlier (see Fig. 3a) was removed (Spearman rank correlation: $\left.249 \mathrm{r}_{\mathrm{s}}=0.58, \mathrm{~N}=23, \mathrm{P}<0.01\right)$.

250 Overall, juvenile lemon sharks demonstrated repeatability in their social behavior (repeatability=0.49; CI: $251[0.36,0.51] ;$ RLRT $=16.578, \mathrm{P}<0.001)$ when controlling for size, sex, location of capture, time in captivity 252 before observations and period of testing.

\section{DISCUSSION}

255 In this study, we explored the presence of a social personality trait in wild juvenile lemon sharks. In doing 256 so we found that sharks consistently differed from each other in some aspects of their social behavior 257 despite being tested in groups (see Webster and Ward 2011 for mechanisms having the potential to 258 suppress individual differences) over a four-month period. Overall, we found a repeatability of 0.49 , 
which is relatively high (see Bell et al. 2009) and consistent with other studies of wild populations (Bell et

260 al. 2009). In addition, consistent individual differences were still maintained despite changes in group 261 composition. The later result indicates that, at least in the juvenile lemon shark population studied, 262 individual social behavioral types play an important part in the social dynamics of these animals and could 263 have a strong impact on their social behavior in the wild.

264 As mentioned above, social personality has already been investigated in sharks (Jacoby et al. 2014; 265 Wilson et al. 2015). However, our study differs from these other investigations in several important points.

266 First, despite using the same species and age criterion, Wilson et al. (2015) did not find consistency in the 267 social proxies they used. While these contrasting results might be attributed to dissimilarities between 268 populations, there are also several methodological discrepancies between Wilson et al.'s study and ours 269 (e.g. sampling method/frequency and smaller sample size). A convergence of methods, to investigate 270 consistent individual differences in these two juvenile lemon shark populations would be useful. Indeed, 271 the possibility to compare between populations might lead to important insights into causes of emergence 272 and maintenance of animal personality. Second our investigation differs from Jacoby et al.'s (2014) study 273 in which consistent individual differences in the social behavior of juvenile catsharks were detected. 274 While they maintained the composition of social groups in their experiments, we allowed it to vary 275 between trials in ours. This was an important aspect of our experimental design for two reasons. First, we 276 believe that our approach reflects natural social mixing between individuals likely to occur in juvenile 277 lemon shark nurseries. Second it indicated that our observed results were not caused by consistent overall 278 group differences. Similarly, keeping group composition constant between trials to investigate social 279 personality in the catshark (Jacoby et al. 2014) may blur the distinction between individual and group 280 behavior differences as causes for Jacoby et al's observation. This concern is reinforced by the fact that 281 individual catsharks (Scyliorhinus canicula) prefer certain individuals over others (Jacoby et al. 2012b) 282 which might influence individual social tendency based on group composition. However, in contrast to 283 juvenile lemon sharks, in catsharks not mixing group composition and allowing affinity to develop reflects 
their ecology during early life stages. Indeed, they are a sedentary species, that hatch in egg clusters, display high site fidelity and are therefore expected to have a pre-determined and relatively stable social environment (D.M.P. Jacoby personal communication). Therefore, mixing group composition in this system might not be relevant to describe the social dynamic of juvenile catsharks in the wild. This highlights the importance to carefully consider the ecology and natural behavior of the species if one is interested in understanding the consequences of individual differences in behavior in the wild. Nevertheless, the contrast between these two species provides interesting systems to investigate social dynamics in two alternative social systems. Here again, converging methods in future work could be highly beneficial in our understanding of animal personality and social systems in animals. This overall illustrates an unexpected diversity in shark social systems that could provide interesting data if further studied.

Cote et al. (2012) gave individual mosquitofish (Gambusia affinis) a choice between shoals of different sizes and compositions in binary choice experiments and found that despite an effect of these two characteristics, individual differences in sociability were still detectable. Even though our investigation differs in several ways including the choice to let individuals interact together, our results are in agreement with the maintenance of individual differences despite social context changes. It is important to note a relative similarity of what is considered as a social interaction. Indeed, in a binary choice experiment, observers record only "active" attempts of socializing from the focal individual. Similarly, in our experiment, we recorded a behavior as social only when the focal individual actively interacted. Being followed by another individual was not considered as social which led to classify leading as asocial, in contrast to the commonly used gambit of the group, for instance. We believe that this treatment of leading events could be related to the distinction between effective (an individual able to impose its preferences) and intrinsic leaders (the tendency of an individual to pursue its own preference) discussed by Johnston and Manica (2011). However, instead of imposing other individuals to follow, it seems that an intrinsic leader becomes an effective leader only in the presence of followers. This, in turn, suggests that some aspects of individual behavior are relatively fixed even in groups and could play an important part in the 
310 dynamic of social groups (Harcourt et al. 2009a; Laskowski and Bell 2014). However, further tests are 311 needed to investigate this hypothesis in juvenile lemon sharks. It could, for instance, be done by 312 experimentally changing group compositions based on known social personality types and observe how 313 cohesion is impacted (e.g. social network measures and group size), especially in an "extreme" social 314 environment (e.g. only asocial individuals). Continuing this work to understand the influence of 315 individuality on social group dynamic is important as it remains poorly understood. Results from the 316 literature indicate that this is dependent on context and/or species (e.g. Magnhagen and Staffan 2005; 317 Magnhagen and Bunnefeld 2009; Magnhagen 2012; Castanheira et al. 2013; Brown and Irving 2014). For 318 instance, Magnhagen and Staffan (2005) found that in perch (Perca fluviatilis) the boldness score of 319 individual young of the year perch was strongly modified by other group members. On the other hand, 320 Magnhagen and Bunnefeld (2009) found that in 1-year-old perch individual boldness was also expressed 321 while tested in groups. Interestingly, Magnhagen (2012) suggested that the maintenance of individuality in 322 perch social groups might depend on the experience of predation. Unfortunately, most of the experiments 323 focusing on personality in a social context tested other personality axes than sociability (e.g. boldness or 324 exploration). A direct comparison with our study is therefore difficult but these differences between 325 investigations are interesting. If further studied in Teleost fishes and sharks, comparative work could lead 326 to a better understanding of overall social group behavior in animals (Wolf and Krause 2014; Farine et al. 327 2015) while emphasizing the importance of behavioral type into group dynamics.

328 Contrary to expectation, individuals that experienced the same group composition between tests showed a 329 lack of consistency. A potential explanation would be an unforeseen familiarity development during the 330 experimental procedure. This has been demonstrated to influence social interactions in this species (Keller 331 et al. 2017) and in catsharks (Jacoby et al. 2012b). A simpler explanation might, however, be the influence 332 of one outlier and indeed once removed consistency was found.

333 Long-term stability of personality traits has been described in other animals (Koski 2011; Beleyur et al. 334 2015; Debeffe et al. 2015; Wuerz and Kruger 2015) including fish (King et al. 2013; Boulton et al. 2014; 335 Castanheira et al. 2016; Vrtelova et al. 2016). However, only a few studies have demonstrated long-term 
consistency of social behavior in wild populations (see for instance: Cote and Clobert 2007; Aplin et al.

337 2015), as shown here in juvenile lemon sharks. These are interesting results when contrasted with a study 338 by Nakayama et al. (2013), describing that the individual tendency to follow is experimentally changeable 339 (i.e. using reward) in the three-spined stickleback (Gasterosteus aculeatus). If the tendency to follow is 340 plastic and can change depending on experience, one can ask how individual differences are maintained 341 over a long period in the wild (e.g. positive feed-back loop, highly stable environments). Trying to 342 experimentally modify the tendency to follow in juvenile lemon sharks would be an interesting first step 343 in this direction. The demonstration of such long-term consistency is also ecologically important. Indeed, 344 even if a four-month period is relatively short compared to the age of maturity in this species (sexual 345 maturity is reached at 12 years old; Brown and Gruber 1988), the first three years of life (ontogenetic 346 stages of this investigation) represent a critical life-history period for juvenile lemon sharks, due to their 347 high natural mortality (Gruber et al. 2001; Dibattista et al. 2007). Finding individual behavioral 348 consistency during this period suggests that personality could have an impact on everyday life of juvenile 349 lemon sharks. One logical next step would be to investigate the ecological consequences of long-term consistency in juvenile lemon sharks. Nevertheless, longer term tests are still required to confidently conclude that individual differences are indeed stable over the entire three-year period during this life stage. Such long-term studies are overall rare and absent for elasmobranchs. It is, therefore, important to extend such research to further populations and species to better understand stability and the ecological consequences of personality in these animals. This would overall benefit the study of animal personality by giving insights into the emergence and maintenance of individual differences (e.g. Dall et al. 2004; 356 Stamps 2007; Wolf et al. 2007; Bergmuller and Taborsky 2010; Dingemanse and Wolf 2010).

357 Overall, this study has shown that individual juvenile lemon sharks vary in their tendency to socialize in a 358 consistent manner. Consistency was maintained despite changes in group composition. These results 359 indicate a potential strong impact of individuality on group behavior. It could be rewarding to extend this 360 approach to other taxa and investigate in which circumstances consistency takes over plasticity in the 361 tendency to socialize. Furthermore, the fact that these variations between individuals persist through 
relatively long-time periods suggests that personality is an important aspect of sharks' behavior that could

363 have both ecological and evolutionary impacts. Finally, these results show that the behavioral complexity 364 of sharks (and other elasmobranchs) is underestimated and that this taxonomic group deserves more 365 attention.

\section{ACKNOWLEDGMENTS}

We thank the volunteers and staff members of the Bimini Biological Field Station Foundation for their invaluable support. We are grateful to David Jacoby, Charlie Huveneers and one anonymous referee for their comments on the manuscript, and Ralf Kurvers for his advice on the study design.

\section{Compliance with ethical standards}

372 Ethical statement No sharks died during the experiments, and all were released at their site of capture

373 with their color tags removed. All manipulations (e.g. size/sex determination and tagging) were performed 374 within five minutes to minimize stress. All procedures were approved by the Department of Marine 375 Resources, Bahamas (Permit no: MAF/LIA/22). No steps required anaesthetizing the animals as this 376 would increase manipulation time, increasing the stress on the animal.

377 Funding This work was supported by the Elsa-Neumann-Stipendium des Landes Berlin; the Save Our 378 Seas Foundation; the Guy Harvey Ocean Foundation and the B-types project (SAW-2013-IGB-2) funded 379 through the Leibniz Competition.

380 Conflict of interest The authors declare that they have no conflict of interest.

381 Ethical approval All applicable guidelines for the care and use of animals were followed. 
384 The datasets analyzed during the current study are available in the open science framework repository, 385 https://osf.io/7w4mx/. The algorithm used in this study is not publicly available but could be available 386 from the corresponding author on reasonable request. This is to prevent potential misuse of this non387 friendly-user code only adapted to the swimming characteristics of the juvenile lemon sharks.

401 Aplin LM, Firth JA, Farine DR et al (2015) Consistent individual differences in the social phenotypes of 402 wild great tits, Parus major. Anim Behav 108:117-127

403 Archard GA, Braithwaite VA (2010) The importance of wild populations in studies of animal 404 temperament. J Zool 281:149-160 
Bates D, Machler M, Bolker BM, Walker SC (2015) Fitting linear mixed-effects models using lme4. J Stat Softw $67: 1-48$

Beleyur T, Bellur DU, Somanathan H (2015) Long-term behavioural consistency in prey capture but not in web maintenance in a social spider. Behav Ecol Sociobiol 69:1019-1028

Bell AM, Hankison SJ, Laskowski KL (2009) The repeatability of behaviour: a meta-analysis. Anim Behav 77:771-783

Bergmuller R, Taborsky M (2010) Animal personality due to social niche specialisation. Trends Ecol Evol

Biro PA, Sampson P (2015) Fishing directly selects on growth rate via behaviour: implications of growth25:504-511

Biro PA, Post JR (2008) Rapid depletion of genotypes with fast growth and bold personality traits from

Brown C, Irving E (2014) Individual personality traits influence group exploration in a feral guppy population. Behav Ecol 25:95-101

Brown CA, Gruber SH (1988) Age assessment of the lemon shark, Negaprion brevirostris, using tetracycline validated vertebral centra. Copeia 1988:747-753 portusjacksoni. J Fish Biol 89:1142-1157 sharks (Heterodontus portusjacksoni). Behav Brain Res 305:239-246 the link between elasmobranch personality and laterality. Behaviour 153:1777-1793 
Castanheira MF, Herrera M, Costas B, Conceicao LEC, Martins CIM (2013) Can we predict personality in fish? Searching for consistency over time and across contexts. PLoS ONE 8:e62037

Castanheira MF, Paramo SM, Figueiredo F, Cerqueira M, Millot S, Oliveira CCV, Martins CIM, Conceicao LEC (2016) Are coping styles consistent in the teleost fish Sparus aurata through sexual maturation and sex reversal? Fish Physiol Biochem 42:1441-1452

Chapman DD, Babcock EA, Gruber SH, Dibattista JD, Franks BR, Kessel SA, Guttridge T, Pikitch EK, Feldheim KA (2009) Long-term natal site-fidelity by immature lemon sharks (Negaprion brevirostris) at a subtropical island. Mol Ecol 18:3500-3507

Conrad JL, Weinersmith KL, Brodin T, Saltz JB, Sih A (2011) Behavioural syndromes in fishes: a review with implications for ecology and fisheries management. J Fish Biol 78:395-435

Cote J, Clobert J (2007) Social personalities influence natal dispersal in a lizard. Proc R Soc Lond B

Cote J, Fogarty S, Sih A (2012) Individual sociability and choosiness between shoal types. Anim Behav

Croft DP, Madden JR, Franks DW, James R (2011) Hypothesis testing in animal social networks. Trends

Dall SRX, Houston AI, McNamara JM (2004) The behavioural ecology of personality: consistent Ecol Evol 26:502-507 individual differences from an adaptive perspective. Ecol Lett 7:734-739

Debeffe L, Lemaitre JF, Bergvall UA et al (2015) Short- and long-term repeatability of docility in the roe deer: sex and age matter. Anim Behav 109:53-63

Dibattista JD, Feldheim KA, Gruber SH, Hendry AP (2007) When bigger is not better: selection against large size, high condition and fast growth in juvenile lemon sharks. J Evol Biol 20:201-212

Dingemanse NJ, Wolf M (2010) Recent models for adaptive personality differences: a review. Philos T Roy Soc B 365:3947-3958 rays. eLife 3:e0590 
Estes JA, Terborgh J, Brashares JS et al (2011) Trophic downgrading of planet earth. Science 333:301306

Farine DR, Montiglio PO, Spiegel O (2015) From individuals to groups and back: the evolutionary implications of group phenotypic composition. Trends Ecol Evol 30:609-621

Finger JS, Dhellemmes F, Guttridge TL (2017) Personality in elasmobranchs with a focus on sharks: early evidence, challenges, and future directions. In: Vonk J, Weiss A, Kuczaj SA (eds) Personality in Nonhuman Animals. Springer, Berlin, pp 129-152

Finger JS, Dhellemmes F, Guttridge TL, Kurvers R, Gruber SH, Krause J (2016) Rate of movement of juvenile lemon sharks in a novel open field, are we measuring activity or reaction to novelty? Anim Behav 116:75-82

Gosling SD (2001) From mice to men: What can we learn about personality from animal research? Psychol Bull 127:45-86

Gruber SH, de Marignac JRC, Hoenig JM (2001) Survival of juvenile lemon sharks at Bimini, Bahamas, estimated by mark-depletion experiments. Trans Am Fish Soc 130:376-384

Guttridge TL, Gruber SH, DiBattista JD, Feldheim KA, Croft DP, Krause S, Krause J (2011) Assortative interactions and leadership in a free-ranging population of juvenile lemon shark Negaprion brevirostris. Mar Ecol-Prog Ser 423:235-245

Guttridge TL, Gruber SH, Gledhill KS, Croft DP, Sims DW, Krause J (2009) Social preferences of juvenile lemon sharks, Negaprion brevirostris. Anim Behav 78:543-548

Harcourt JL, Ang TZ, Sweetman G, Johnstone RA, Manica A (2009a) Social feedback and the emergence of leaders and followers. Curr Biol 19:248-252

Harcourt JL, Sweetman G, Johnstone RA, Manica A (2009b) Personality counts: the effect of boldness on shoal choice in three-spined sticklebacks. Anim Behav 77:1501-1505

Huveneers C, Rogers PJ, Beckmann C, Semmens JM, Bruce BD, Seuront L (2013) The effects of cagediving activities on the fine-scale swimming behaviour and space use of white sharks. Mar Biol $160: 2863-2875$ 
Jacoby DMP, Croft DP, Sims DW (2012a) Social behaviour in sharks and rays: analysis, patterns and implications for conservation. Fish Fish 13:399-417

Jacoby DMP, Fear LN, Sims DW, Croft DP (2014) Shark personalities? Repeatability of social network traits in a widely distributed predatory fish. Behav Ecol Sociobiol 68:1995-2003

Jacoby DMP, Sims DW, Croft DP (2012b) The effect of familiarity on aggregation and social behaviour in juvenile small spotted catsharks Scyliorhinus canicula. J Fish Biol 81:1596-1610

Johnstone RA, Manica A (2011) Evolution of personality differences in leadership. P Natl Acad Sci USA $108: 8373-8378$

Keller BA, Finger JS, Gruber SH, Abel DC, Guttridge TL (2017) The effects of familiarity on the social interactions of juvenile lemon sharks, Negaprion brevirostris. J Exp Mar Biol Ecol 489:24-31

King AJ, Furtbauer I, Mamuneas D, James C, Manica A (2013) Sex-differences and temporal consistency in stickleback fish boldness. PLoS ONE 8:e81116

Klimley AP (1985) Schooling in Sphyrna lewini, a species with low risk of predation: a non-egalitarian state. Z Tierpsychol 70:297-319

Koski SE (2011) Social personality traits in chimpanzees: temporal stability and structure of behaviourally assessed personality traits in three captive populations. Behav Ecol Sociobiol 65:2161-2174

Krause J, Ruxton GD (2002) Living in groups. Oxford University Press, Oxford Personality differences explain leadership in barnacle geese. Anim Behav 78:447-453

Laskowski KL, Bell AM (2014) Strong personalities, not social niches, drive individual differences in social behaviours in sticklebacks. Anim Behav 90:287-295 marine megafauna. Trends Ecol Evol 19:598-604 shoaling fishes? Curr Zool 58:35-44 
Magnhagen C, Bunnefeld N (2009) Express your personality or go along with the group: what determines the behaviour of shoaling perch? Proc R Soc Lond B 276:3369-3375

Magnhagen C, Staffan F (2005) Is boldness affected by group composition in young-of-the-year perch (Perca fluviatilis)? Behav Ecol Sociobiol 57:295-303

Manire CA, Gruber SH (1991) Effect of M-type DART tags on field growth of juvenile lemon sharks. Trans Am Fish Soc 120:776-780

513 Matich P, Heithaus MR (2015) Individual variation in ontogenetic niche shifts in habitat use and movement patterns of a large estuarine predator (Carcharhinus leucas). Oecologia 178:347-359

515 Meijering E, Dzyubachyk O, Smal I (2012) Methods for cell and particle tracking. Methods Enzymol $516 \quad 504: 183-200$

517 Mittelbach GG, Ballew NG, Kjelvik MK (2014) Fish behavioral types and their ecological consequences.

$518 \quad$ Can J Fish Aquat Sci 71:927-944

519 Morrissey JF, Gruber SH (1993) Home range of juvenile lemon sharks, Negaprion brevirostris. Copeia 1993:425-434

521 Mourier J, Bass NC, Guttridge TL, Day J, Brown C (2017) Does detection range matter for inferring social networks in a benthic shark using acoustic telemetry? Royal Soc Open Sci 4:170485

523 Mourier J, Vercelloni J, Planes S (2012) Evidence of social communities in a spatially structured network 524 of a free-ranging shark species. Anim Behav 83:389-401

525 Mucientes GR, Queiroz N, Sousa LL, Tarroso P, Sims DW (2009) Sexual segregation of pelagic sharks 526 and the potential threat from fisheries. Biol Lett 5:156-159

527 Myrberg AA, Gruber SH (1974) The behavior of the bonnethead shark, Sphyrna tiburo. Copeia 1974:358$528 \quad 374$

529 Nakagawa S, Schielzeth H (2010) Repeatability for Gaussian and non-Gaussian data: a practical guide for $530 \quad$ biologists. Biol Rev 85:935-956

531 Nakayama S, Stumpe MC, Manica A, Johnstone RA (2013) Experience overrides personality differences 532 in the tendency to follow but not in the tendency to lead. Proc R Soc B 280:20131724 
533 Northcutt RG (1977) Elasmobranch central nervous system organization and its possible evolutionary $534 \quad$ significance. Am Zool 17:411-429

535 Pritchard VL, Lawrence J, Butlin RK, Krause J (2001) Shoal choice in zebrafish, Danio rerio: the 536 influence of shoal size and activity. Anim Behav 62:1085-1088

537 Rasband W (1997) ImageJ. US National Institutes of Health, Bethesda, MD

538 Réale D, Reader SM, Sol D, McDougall PT, Dingemanse NJ (2007) Integrating animal temperament 539 within ecology and evolution. Biol Rev 82:291-318

540 Scheipl F, Greven S, Kuchenhoff H (2008) Size and power of tests for a zero random effect variance or 541 polynomial regression in additive and linear mixed models. Comput Stat Data Anal 52:3283-3299 542 Sih A, Bell AM, Johnson JC, Ziemba RE (2004) Behavioral syndromes: An integrative overview. Q Rev $543 \quad$ Biol 79:241-277

544 Sih A, Cote J, Evans M, Fogarty S, Pruitt J (2012) Ecological implications of behavioural syndromes. $545 \quad$ Ecol Lett 15:278-289

546 Stamps J, Groothuis TGG (2010) The development of animal personality: relevance, concepts and 547 perspectives. Biol Rev 85:301-325

548 Stamps JA (2007) Growth-mortality tradeoffs and 'personality traits' in animals. Ecol Lett 10:355-363

549 Stevens JD, Bonfil R, Dulvy NK, Walker PA (2000) The effects of fishing on sharks, rays, and chimaeras 550 (chondrichthyans), and the implications for marine ecosystems. ICES J Mar Sci 57:476-494

551 Sutter DAH, Suski CD, Philipp DP, Klefoth T, Wahl DH, Kersten P, Cooke SJ, Arlinghaus R (2012) 552 Recreational fishing selectively captures individuals with the highest fitness potential. P Natl $553 \quad$ Acad Sci USA 109:20960-20965

554 Towner AV, Leos-Barajas V, Langrock R, Schick RS, Smale MJ, Kaschke T, Jewell OJD, Papastamatiou 555 YP (2016) Sex-specific and individual preferences for hunting strategies in white sharks. Funct 556 Ecol 30:1397-1407 
Vaudo JJ, Wetherbee BM, Harvey G, Nemeth RS, Aming C, Burnie N, Howey-Jordan LA, Shivji MS (2014) Intraspecific variation in vertical habitat use by tiger sharks (Galeocerdo cuvier) in the western North Atlantic. Ecol Evol 4:1768-1786

Vrtelova J, Ferrari MCO, Manek AK, Chivers DP (2016) Consistent long-term behavioural traits are linked to morphological defences in common carp (Cyprinus carpio). Behaviour 153:15-30

Webster MM, Ward AJW (2011) Personality and social context. Biol Rev 86:759-773

Wilson ADM, Brownscombe JW, Krause J, Krause S, Gutowsky LFG, Brooks EJ, Cooke SJ (2015) Integrating network analysis, sensor tags, and observation to understand shark ecology and behavior. Behav Ecol 26:1577-1586

Wilson ADM, Krause S, James R, Croft DP, Ramnarine IW, Borner KK, Clement RJG, Krause J (2014) Dynamic social networks in guppies (Poecilia reticulata). Behav Ecol Sociobiol 68:915-925

Wolf M, Krause J (2014) Why personality differences matter for social functioning and social structure. Trends Ecol Evol 29:306-308

Wolf M, van Doorn GS, Leimar O, Weissing FJ (2007) Life-history trade-offs favour the evolution of animal personalities. Nature 447:581-584

Wolf M, Weissing FJ (2012) Animal personalities: consequences for ecology and evolution. Trends Ecol Evol 27:452-461

Wuerz Y, Krüger O (2015) Personality over ontogeny in zebra finches: long-term repeatable traits but unstable behavioural syndromes. Front Zool 12:S9

Yopak KE, Lisney TJ, Collin SP, Montgomery JC (2007) Variation in brain organization and cerebellar foliation in chondrichthyans: Sharks and holocephalans. Brain Behav Evol 69:280-300 


\section{$596 \quad$ Figure legend}

597 Fig. 1 Schematic of the experimental setup in Bimini, Bahamas with holding pen (A) separated into 598 compartments containing size-matched sharks, linked to the experimental pen (B), via channel. On both 599 sides of the social pen, there are two vertical wooden posts (brown squares) linked by ropes (dashed lines) 600 used to raise and slide the camera (black box) above the center of the experimental pen. Identification of 601 individuals and camera operation are performed from a wooden tower (C)

602 Fig. 2 Comparison of sociability score for juvenile lemon sharks in Bimini, Bahamas between trial 1 and 603 trial 2 for short-term (a) and long-term (b) test retests 
604 Fig. 3 Comparison of sociability scores between trial 1 and trial 2 for short-term showing individual 605 juvenile lemon sharks (Bimini, Bahamas) that experienced no change (a) and change (b) in group 606 composition between test and retests. The circle identifies a potential outlier mentioned in the text above

Behavioral State Definition Included as social score

607

608

609

610

611

612

613

614

615

616

617

618

619

620

621 Table 1 Social behavior of juvenile lemon sharks. Each of these behaviors is only considered when

622 individuals are within 2.5 body lengths of each other. Table modified from Guttridge et al. (2011) 


\begin{tabular}{ccc}
\hline Following & An individual mimics trajectory of followed & Yes \\
& Individual. & \\
Paralleling & similar speed or while overtaking/being \\
overtaken. & Yes \\
Milling & Individuals swimming in a non-coordinated & No \\
\hline Leading & Being followed but not paralleling or & No \\
& following another individual. & \\
\hline
\end{tabular}

623 